\title{
GLOBALIZANDO A IDADE DO FERRO MEDITERRÂNEA 1
}

\author{
Tamar Hodos ${ }^{2}$
}

\begin{abstract}
Resumo
A Idade do Ferro Mediterrânea (c. 1200-600 AEC) foi um dos seus períodos mais dinâmicos. Embora não tenha sido a primeira era na qual seus habitantes trocaram bens, ideias, valores, costumes, práticas e tecnologias, a escala foi sem precedentes. Em grande parte, o período é caracterizado por assentamentos gregos e fenícios ao redor de todo o mar, facilitando uma comunicação frequente e ampla. O impacto a longo prazo foi a criação do primeiro período globalmente conectado do Mediterrâneo. Entretanto, uma era globalizada nem sempre foi a narrativa apresentada pelos estudiosos. O presente capítulo começa definindo globalização e avaliando oito tendências fundamentais que ocorrem na globalização contemporânea. Depois, ele esboça a Idade do Ferro Mediterrânea e a nossa história acadêmica na interpretação dos movimentos coloniais gregos e fenícios, de perspectivas colonialistas até pós-coloniais. Finalmente, ele explora como as teorias de globalização contemporâneas podem transformar a nossa compreensão desta época culturalmente complexa e socialmente vibrante.
\end{abstract}

\section{Palavras-Chave}

Idade do Ferro Mediterrânea; globalização; colonização; hibridização; colonialismo; pós-colonialismo.

\footnotetext{
${ }^{1}$ Tradução - Anabelle Silvana Luzardo Medeiros y Rosa Maria Severino Ueno.

${ }^{2}$ Doutora - Universidade de Bristol, Bristol, Reino Unido. E-mail: t.hodos@bristo.ac.uk

Heródoto, Unifesp, Guarulhos, v.4, n.1 - 2019.1. p. 45-73

DOI: $10.34024 /$ herodoto.\%Y.v\%v.10087 


\section{Resumen}

La Edad del Hierro en el Mediterráneo (c. 1200-600 AEC) es uno de los períodos más dinámicos. Aunque no fue la primera era en la que sus habitantes intercambiaron mercancías, ideas, valores, costumbres, prácticas y tecnologías, la escala fue sin precedentes. El período se caracteriza, sobre todo, por el asentamiento griego y fenicio alrededor de todo el mar, lo que facilitó una amplia y frecuente comunicación. El impacto a largo plazo fue la creación del primer período conectado a escala global del Mediterráneo. Sin embargo, los académicos no nos han presentado, hasta ahora, una era globalizada. Este capítulo comienza con la definición de globalización y evalúa ocho tendencias fundamentales que se producen en la globalización contemporánea. Describe luego la Edad del Hierro del Mediterráneo y nuestros antecedentes académicos en la interpretación de los movimientos coloniales griegos y fenicios, desde la concepción colonial hasta la poscolonial. Por último, analiza cómo las teorías de la globalización contemporánea pueden transformar nuestro entendimiento de esta era culturalmente compleja y socialmente pujante.

\section{Palabras clave}

Edad del Hierro en el Mediterráneo; Globalización; Colonización; Hibridación; Colonialismo; Poscolonialismo. 


\section{Definindo globalização}

Atualmente, a globalização é um dos mais importantes processos de integração econômica, social e cultural no mundo, envolvendo o comércio, capital e investimentos, migração de mão-de-obra e a disseminação de conhecimento. Muitos diriam que ela acontece por meio do comércio livre e do capitalismo (Cf. Steiglitz, 2006: 3-24; Ward, England, 2007: 1-22; Pieterse, 2014: 1-11). No entanto, a globalização é mais do que apenas uma outra maneira de descrever o neoliberalismo contemporâneo. Na verdade, não há nenhum consenso sobre a definição de globalização, embora muitos a caracterizem, sendo o aumento da conectividade amplamente considerado sua maior característica (Cf. Giddens, 1990; Robertson, 1992; Moore, Lewis, 2009). Esta conectividade é especificamente de um tipo que inclui um fluxo em grande escala de ideias e conhecimento juntamente com a partilha de costumes culturais e práticas da sociedade civil. Esses fluxos e conexões podem se manifestar através de uma integração econômica mais próxima através de um maior movimento de bens e serviços, capital e mão-de-obra ou podem ser moldados pela política (Steiglitz, 2006: 05).

No entanto, muitos debatem as características da globalização, como, por exemplo, se ela é informada por mudanças tecnológicas, envolve a reconfiguração de estados, acontece juntamente com a regionalização ou inclui um sentimento de compressão no tempo e no espaço (Cf. Pieterse, 2015: 7-25). Normalmente, a globalização é descrita e discutida em um contexto disciplinar específico, então, ouvimos falar de diferentes tipos de globalização; tais como: globalização financeira, comercial, econômica ou política. A maioria de nós irá pelo menos concordar que a globalização é desigual e assimétrica em velocidade, escopo e impacto. Os acadêmicos entendem esses desenvolvimentos como um processo (como, por exemplo, Robbie Robertson; Jan Nederveen Pieterse), como um sistema (Jonathan Friedman; Immanuel Wallerstein), como um discurso (Manfred Steger). ${ }^{3}$

O sociólogo cultural Tomlinson define globalização simplesmente como conectividades complexas (Tomlinson, 1992: 02). O sociólogo Roland Robertson, por outro lado, define globalização como o processo pelo qual, cada vez mais, o mundo é visto como um lugar e as maneiras pelas quais ficamos conscientes desse processo (Robertson, 1992: 08). Embora, como o sociólogo Mike Featherstone já mencionou, isso não deveria significar

\footnotetext{
${ }^{3}$ Nederveen Pieterse, Globalization and Culture, Tabelas 1.6 e 1.7, 19-20, com referências em 183-210.
}

Heródoto, Unifesp, Guarulhos, v.4, n.1 - 2019.1. p. $45-73$

DOI: $10.34024 /$ herodoto.\%Y.v\%v.10087 
que há uma cultura mundial unificada (Featherstone, 1995: 114). Por esta razão, o acadêmico especializado em estudos globais e sociologia, Jan Nederveen Pieterse, define globalização como "um processo de hibridização que provoca uma mélange global" (Pieterse, 2015: 67) e argumenta que a globalização pode ser entendida como uma síntese em aberto de várias abordagens disciplinares a tais acontecimentos, nos quais há tantas modalidades de globalização quanto agentes, dinâmicas e impulsos (Pieterse, 2015: 68).

Em outros trabalhos, eu defini globalização como "os processos de conectividades crescentes que se desdobram e manifestam como uma conscientização social dessas conectividades. " (Hodos, 2017: 03-11, 04). Já argumentei que como a globalização se trata dos processos propriamente ditos, trata-se de um conceito ativo e não descritivo. Também comentei que a ideia sugere uma escala mundial e é por isso que alguns insistem tratar-se de um fenômeno que começa apenas com o surgimento da circum-navegação global (Cf. Giddens, 1990; Wallerstein, 1991; Robertson, 2003; Hodos, 2017: 54-65). Todavia, é mais comumente utilizada para refletir mudanças mais abrangentes em um mundo conceitual ou experiente. Muito frequentemente, isso envolve aumentar a integração e cooperação derivadas de práticas comuns, em evolução, que facilitam tal integração e cooperação (Hodos, 2017: 04). Isso não é para sugerir que a conectividade e conscientização de tais conexões sozinhas tornem um período ou local globalizado. Contribuições para o recente Routledge Handbook of Archaeology and Globalization demonstram que a natureza das conexões complexas e como a conscientização social delas é manifestada são o que determina se uma era no passado pode ser considerada globalizada ou não (Hodos, 2017).

Um corolário importante para a crescente sensação de similaridade, acessibilidade e uniformidade que associamos à globalização é a conscientização, e até mesmo o aumento, das diferenças e desigualdades mais acentuadas com aqueles não tão integrados à esfera empírica ou aqueles que nem estão envolvidos. Isto indica que há dois aspectos primários dos processos de globalização: 1 . O desenvolvimento de práticas e valores compartilhados que contribuem para o sentimento de "estar em apenas um lugar"; 2. Maior conscientização e sensibilidade às diferenças, especialmente, às diferenças culturais. Ambos derivam de uma variedade de conectividades crescentes, embora seja o primeiro que, normalmente, receba mais atenção. No entanto, a conscientização crescente da diferença cultural é uma função da globalização e não meramente uma característica dela. Normalmente, isto se manifesta como 
o ressurgimento de práticas locais de identidade em contraste explícito às práticas, cada vez mais, compartilhadas do nível conectado globalmente. Essas expressões locais de identidade também são comumente ligadas a níveis extremamente divergentes de riqueza, saúde e poder político. Como resultado disso, frequentemente, tais acontecimentos aumentam os contrastes entre as partes envolvidas no sistema global e o grau de investimento social para manter as diferenças culturais. Portanto, a globalização mantém um equilíbrio entre as práticas compartilhadas e vinculantes e as diversidades que diferenciam os participantes. Não apenas estão as duas em constante tensão entre si, mas elas também são interdependentes e juntas criam o paradoxo da globalização (Hodos, 2017: 05). A globalização não pode ser conceitualizada ou adequadamente discutida sem levar em conta os dois aspectos. Entretanto, muitas discussões acadêmicas e populares sobre globalização apenas reconhecem o primeiro e ignoram o segundo.

\section{Identificando a globalização}

O arqueólogo Justin Jennings identifica oito tendências que ocorrem na globalização contemporânea (Cf. Jennings, 2011: 123-141; Jennings in: Hodos, 2017: 12-28, 14-16). Elas se sobrepõem e são estimuladas por uma conectividade complexa para criar uma cultura global. Ele argumenta que todas deveriam estar presentes para que qualquer período seja considerado uma era de globalização.

(1) compressão no tempo e no espaço. Identificada pelo geógrafo David Harvey (1989), esta é a experiência de ver seu mundo encolher através da aceleração de processos econômicos, políticos e sociais de longa distância, tais que, mudanças em um local podem ter ramificações em uma região bem ampla. A Internet é um desses exemplos que contribui para o nosso sentimento moderno de compressão no tempo e no espaço. As repercussões da crise financeira de 2008 em todo o mundo ocidental são um outro exemplo. A introdução de uma nova matilha (ou bando) ou a adoção de um sistema de registros tinha efeitos semelhantes no passado.

(2) desterritorialização. Este é o sentimento de que um local parece menos fortemente conectado ao seu contexto local, geograficamente fixo. Ela ocorre através do aumento das redes sociais e da incorporação de pessoas, ideias, práticas e bens estrangeiros a uma configuração local. Atualmente, um efeito da desterritorialização é o cosmopolitanismo das chamadas cidades internacionais ao redor do mundo, para as quais as amarras a uma localização única e fixa são reduzidas devido a uma 
quantidade enorme de interações de longa distância, que une um desses locais a outras cidades e regiões em outras partes do mundo. Desta forma, Paris, como um centro cosmopolita de moda, cultura, artes e culinária, tem pouco a ver com sua localização geográfica e, em relação a isso, é mais fracamente conectada aos seus arredores rurais do que a outros centros cosmopolitas de moda, cultura, artes e culinária, como Nova Iorque, Londres ou Tóquio. No passado, a quantidade e variedade de estilos importados de produtos materiais em certas épocas fomentou a mesma impressão.

(3) padronização. Isso se desenvolve quando pessoas buscam meios de superar divisões geográficas e socioculturais. Padrões universais de medida, como o Tempo Médio de Greenwich (Greenwich Mean Time GMT) ou o sistema métrico, são exemplos que utilizamos atualmente. No passado, as línguas administrativas ajudavam a promover a padronização em vastos territórios compostos por diversos grupos culturais.

(4) desigualdade. A globalização não é um processo uniforme em termos de inclusão. Isso ocorre porque as redes de interação inter-regionais não são geograficamente ubíquas. Consequentemente, pode haver consideráveis diferenciais de poder entre as regiões engajadas. Atualmente a China, por exemplo, domina muitas relações comerciais, enquanto outros países permanecem relativamente isolados, apesar de seu envolvimento em trocas globais, como, por exemplo, o Haiti. Bollywood tem influência global, mas a indústria cinematográfica iraniana, não. No passado, isso era percebido na forma como uma cidade podia exercer maior influência do que outros lugares de sua época, além de desigualdades na propagação de horizontes estilísticos.

(5) homogeneização. Esta talvez seja a marca dos processos de globalização mais amplamente discutida e aquela à qual os indivíduos e a mídia mais reagem. Um certo grau de homogeneização cultural ocorre quando as pessoas começam a compartilhar um conjunto semelhante de práticas e produtos para gerenciar um tráfego crescente de ideias, objetos e pessoas. No entanto, não se trata tanto de um único modo de vida. Ao contrário, ela está relacionada a como entramos em contato com ideias e bens amplamente compartilhados e como os tornamos nossos em nossos contextos locais. Uma visita ao McDonalds na Europa ou na Ásia, por exemplo, pode inicialmente ser uma aventura nova e exótica, mas, com o passar do tempo, uma ida ao McDonalds torna-se tão incorporada às práticas locais que passa a ser uma prática nativa, ao invés de ser vista como um emblema estrangeiro (Caldwell, 2004: 05-26). Atitudes em

Heródoto, Unifesp, Guarulhos, v.4, n.1 - 2019.1. p. $45-73$

DOI: $10.34024 /$ herodoto.\%Y.v\%v.10087 
conformidade com as práticas e valores sociais, como no que se refere à beleza ou violência, são outros exemplos contemporâneos. No passado, isso ocorria por meio de práticas convergentes entre grupos diversificados, como o uso de objetos e estilos parecidos.

(6) heterogeneidade cultural. Isto ocorre porque, juntamente com a homogeneização crescente, muitas vezes, a variação cultural aumenta ao mesmo tempo, especialmente, quando as práticas são reinterpretadas localmente. A mistura das influências externas com as práticas locais varia de local para local. Assim, a yoga é reinterpretada nas academias americanas e os hambúrgueres no Japão não são exatamente o que reconheceríamos no Ocidente. No passado, isso era bem exemplificado por meio de variações visuais nas cerâmicas que misturavam uma série de ideias.

(7) reinserção da cultura local. Isto poderia ser visto como o ressurgimento, ou mesmo a invenção, das práticas e formas locais em uma explícita reação à homogeneização promovida pela crescente globalização. Atualmente, por exemplo, a Académie Française mantém a pureza da língua francesa. No passado, isto era encontrado na reafirmação das tradições locais, como nas formas de sepultamento, na organização dos assentamentos e em outras práticas.

(8) vulnerabilidade. As inúmeras e profundamente incorporadas conexões entre vários grupos que criam uma circunstância de conectividade complexa também levam à interdependência e, portanto, ao risco. A conscientização dos riscos da globalização se torna intensa quando um evento reverbera por toda a rede. Os desafios perante a GrãBretanha devido à sua saída da União Europeia, que continuarão até bem depois de sua saída, ressaltam a vulnerabilidade das conexões complexas atuais, que foram criadas pela rede globalizada que é a União Europeia. No passado, quando centros fortes como Roma fraquejavam, o sistema globalizado de trocas que ele havia criado ao seu redor se partia em redes menores que operavam em uma escala mais restrita.

Jennings argumenta que todas elas precisam estar presentes para que a globalização possa ser identificada. Mas o que define se elas estão presentes? Na verdade, quase todas essas oito características são fáceis de encontrar no passado de maneiras que são comparáveis às nossas experiências nos dias atuais. Embora um aspecto seja mais difícil do que outros, precisamente, em razão de como vivenciamos isso hoje e esta é a ideia de compressão no tempo e no espaço. Recentes desenvolvimentos tecnológicos tornaram o mundo atual mais fácil e rapidamente conectado.

Heródoto, Unifesp, Guarulhos, v.4, n.1 - 2019.1. p. $45-73$

DOI: $10.34024 /$ herodoto.\%Y.v\%v.10087 
Nossa habilidade de nos comunicarmos com todo o planeta faz com que o tempo e o espaço pareçam comprimidos em uma experiência imediata e amplamente compartilhada, tanto que o mundo parece menor do que há uma geração. Como há poucas evidências de tal aumento dramático na velocidade da comunicação no passado, algumas pessoas argumentam que, portanto, a globalização só pode ser um fenômeno bastante moderno e desafiam sua aplicação ao passado (Cf. Morley in: Pitts e Versluys, 2014: 49-68). Outros que focam na sua escala geográfica sugerem que ela não pode anteceder o século XVI e a circum-navegação do mundo (Cf. Giddens, 1990; Wallerstein, 1991; Robertson, 2003; Hodos, 2017: 54-65), proclamando a era europeia de descobrimentos, embora isso privilegie as noções ocidentais no nosso entendimento da globalização.

A compressão no tempo e no espaço em si pode ser desafiada pela fenomenologia, o estudo das estruturas da experiência e nossa consciência da experiência, porque o mundo não está encolhendo ou se contraindo fisicamente como um resultado da globalização. Esta impressão deriva da comunicação mais rápida entre os grupos, que criou a sensação de que o mundo está menor, pois leva menos tempo para nos comunicarmos hoje do que antes. Em outras palavras, para a maioria das pessoas, a experiência cultural da globalização não deriva de sua própria mobilidade direta.

Como não estamos realmente vivenciando a compressão do tempo e espaço, o que estamos vivenciando? Alguém poderia argumentar que se trata de um sentimento de "estar em apenas um lugar" (Hodos in: Pitts e Versluys, 2014: 240-253). Podemos nos comunicar com alguém do outro lado do mundo em um instante, como se estivéssemos no mesmo lugar. Anteriormente, o surgimento do telefone tornou possível conversar diretamente com alguém bem distante. Redes de rotas de navegação de longa distância, estradas e vias tiveram a mesma finalidade no passado mais distante. Elas ajudavam lugares longínquos a se sentirem conectados, assim como a comunicação rápida faz hoje em dia. Contudo, há outras maneiras de transmitir essa conexão, esse sentimento de "estar em apenas um lugar". Na antiguidade, a maioria das pessoas não viajava para muito longe, se de fato viajassem. Do contrário, as redes de práticas compartilhadas transmitiram essa noção de "estar em apenas um lugar". Para exemplificar, no mundo romano, a rapidez das viagens e da comunicação não aumentava substancialmente por todo o império romano quando uma região era incorporada a ele, apesar da construção de malhas viárias (Cf. Morley in: Pitts e Versluys, 2014: 49-68). Todavia, houve um aumento na frequência da comunicação, o que levou ao 
aumento das informações sobre as regiões, rotas e preços, bem como mais movimentos frequentes de itens e serviços compartilhados. Isso resultou em bens e práticas mais difundidos, o que criou um sentimento de "estar em apenas um lugar". É por meio das redes de práticas e bens comuns que as pessoas vivenciam a sensação de compressão do tempo e espaço em uma experiência compartilhada, vivida.

\section{A Idade do Ferro Mediterrânea}

Apesar de seu nome, o Idade do Ferro Mediterrânea não está rigorosamente correlacionada ao desenvolvimento da siderurgia, uma vez que o ferro já era conhecido no quinto e quarto milênios AEC no Irã (Sialk), Iraque (Samarra) e Egito (Gerzeh) e no terceiro milênio na Mesopotâmia e Anatólia (Tilmen Höyük; Alaca Höyük) (Waldbaum, 1978; Waldbaum in: Piggot, 1999: 27-57; Yalçın, 1999: 177-187). Pelo contrário, o termo "Idade do Ferro" é tido como um meio de marcar modificações nas tradições e práticas associadas a seus antecedentes temporais. O que se seguiu foram mudanças nas práticas sociais, evidenciadas nos fósseis materiais, principalmente, através de novas formas e estilos de cerâmica, formas arquitetônicas e práticas de sepultamento. Tais modificações não ocorreram em um só momento, mas se desenvolveram ao longo do tempo, e a taxa de mudança em qualquer categoria material não era uniforme de local a local ou de região para região. Portanto, o conceito da Idade do Ferro é algo relacional.

Para o Mediterrâneo, essa ruptura ocorre no final do século XII AEC, que é considerado o final da Idade do Bronze. Isto resultou no fim do sistema palaciano micênico no Egeu, na desintegração do Império Hitita em Anatólia e Mesopotâmia, na invasão do Egito e da costa oriental do Mediterrâneo por aqueles denominados Povos do Mar e no fim da Nova Época do Reinado Egípcio. Contatos mais difundidos entre essas comunidades diminuíram drasticamente, especialmente, quando comparados à quantidade de bens, ideias e pessoas em circulação que tanto precederam e sucederam os séculos por volta do início do primeiro milênio AEC. Coletivamente, isso faz parte do que cria um sentimento geral de mudança e o que marca o início da Idade do Ferro no Mediterrâneo.

O que mais caracteriza a Idade do Ferro Mediterrânea é o movimento de pessoas, diferenciado pelos números e natureza. Até o século IX AEC, se não antes disso, pessoas e pequenos grupos começaram a se mover ao redor do Mediterrâneo. Algumas dessas pessoas eram comerciantes e 
artesãos itinerantes, mas também vemos o movimento de grupos maiores de pessoas que fixaram residência em litorais estrangeiros. Dois de tais movimentos, que tiveram os maiores impactos, foram os fenícios e os gregos.

Apesar do fato de que os gregos e fenícios estabeleceram assentamentos no exterior, ao longo do Mediterrâneo e, algumas vezes, no mesmo território geográfico (como, por exemplo, na Sicília), o estudo de sua expansão foi dividido entre disciplinas (Hodos, 2009: 221-241). Acadêmicos do Oriente Próximo têm tradicionalmente focado no processo de colonização dos fenícios, enquanto os acadêmicos clássicos examinaram o movimento grego. Essa divisão disciplinar pode ser rastreada até os estudos europeus ocidentais do século XIX e a respectiva primazia das fontes literárias bíblicas e clássicas antigas corroboradas por pesquisas arqueológicas daquela época. Frequentemente, isso é expresso através de uma competição pela primazia na inovação colonial. Sintomático desta rivalidade são perguntas sobre as datas da fundação das colônias mais antigas, feitas como se uma supremacia da inovação dependesse disso. A maioria das fontes literárias antigas nos informa que a expansão dos fenícios no Mediterrâneo começou no século XII AEC, enquanto confirmam que a colonização grega só começou no século VIII (Cf. Hodos, 2009: 221-241; Pieterse, 2015: 7-25). Entretanto, por muito mais de um século, estudiosos gregos argumentaram que a expansão fenícia não poderia ter começado antes do século VIII (Beloch, 1913: 229232), baseado no fato de que evidências materiais não puderam ser identificadas para sustentar assentamentos tão antigos em lugares onde os fenícios deveriam ter colonizado. John Boardman, por exemplo, afirma que:

Apenas depois dos gregos se estabelecerem na costa Síria foi que a Grécia começou a receber e apreciar produtos orientais; e não há evidências claras sobre colônias comerciais fenícias no exterior antes das gregas. Por tudo isso, eles podem ter sido os transportadores do pouco que chegou ao mundo grego do Oriente antes do século VIII. A natureza desse comércio não demandava o estabelecimento de postos ou colônias comerciais tradicionais até que o exemplo grego e a concorrência os levou a fazer empreendimentos semelhantes. (Boardman, 1999: 38).

Mais recentemente, Gocha Tsetskhladze afirmou:

No século VIII a.C., os gregos estavam se mudando para os territórios relativamente próximos da Itália central e meridional, enquanto os fenícios estabeleceram pequenos assentamentos na Sardenha e mais a oeste e ao sul. Os assentamentos gregos foram projetados para durar; os dos fenícios 
desapareceram com o tempo, provavelmente absorvidos pelos povos locais. (Tsetskhladze in: Tsetskhladze, 2006: 23-83, 49).

Esta declaração é limitada em foco e factualmente incorreta, pois ignora os assentamentos fenícios duradouros e substanciais da Sicília, Espanha e Norte da África, bem como as comunidades gregas contemporâneas que não conseguiram sobreviver. Os estabelecimentos fenícios não eram menos "permanentes" do que os gregos. Na verdade, discussões sobre um território em particular são frequentemente formuladas em termos das prioridades gregas ou fenícias. Os estudos acadêmicos tendem a dar pouca consideração à possibilidade de que um local possa ter sido compartilhado entre ambos os grupos, ou qualquer outro povo, apesar do fato de outros já estarem estabelecidos em territórios aos quais os gregos e fenícios chegaram. ${ }^{4}$

Estudos fenícios fizeram mais ou menos o mesmo. Sabatino Moscati, por exemplo, argumentou quase defensivamente em seu trabalho pioneiro sobre o tema que a falta de evidências materiais antes do século VIII (como foi o caso até bem recentemente) não seria razão para duvidar dos textos gregos e bíblicos e registros fenícios que atestam atividades fenícias muito antes disso (Moscati, 1966). A dificuldade surge pelo fato de que a cerâmica é o nosso meio primário de datar sítios e contextos durante esse período. $\mathrm{O}$ problema com as evidências dos assentamentos fenícios, contudo, é que a cerâmica fenícia mudou pouco em estilo ao longo do final do segundo e primeiro milênio e lhe falta a refinada precisão cronológica da cerâmica grega. Portanto, quando cerâmicas fenícias são encontradas, pode ser bastante difícil determinar sua data exatamente. Em contrapartida, em quase todos os lugares onde os gregos se estabeleceram, seus utensílios para beber vinho e outras bebidas - que estão muito bem datados - rapidamente tornaram-se integrados ao gosto e aos costumes locais e a montagem de suas cerâmicas influenciou a produção nativa da região. Além disso, muitos assentamentos adotaram formas arquitetônicas advindas dos gregos. Às vezes, o alfabeto grego era adaptado para expressar línguas locais (embora, originalmente, ele tenha derivado do alfabeto fenício) e, por fim, muitas comunidades pegaram o sistema grego de cunhagem emprestado. Embora os fenícios tenham sido tão prevalentes no Mediterrâneo, sua cultura material não foi amplamente adotada por outros. De fato, o uso de cerâmicas e de ideias arquitetônicas gregas também foram incorporados pelos fenícios em suas práticas e construções urbanas.

${ }^{4}$ Cf. (Boardman, 1999: 213) no que se refere à Espanha.

Heródoto, Unifesp, Guarulhos, v.4, n.1 - 2019.1. p. $45-73$

DOI: $10.34024 /$ herodoto.\%Y.v\%v.10087 
Inicialmente, essa prevalência de formas culturais gregas foi interpretada como um desejo por entendimento e sofisticação culturais das comunidades nativas (e os fenícios, até certo ponto, que eram grandemente desprezados porque faziam parte dos estudos do Oriente Próximo). Isto é muito bem explicado pela descrição de Boardman da interação grega com as populações não estrangeiras da Sicília e Itália, quando ele diz: "No Ocidente, os gregos não tinham nada a aprender, mas muito a ensinar." (Boardman, 1999: 190). Nesse modelo de "Helenização", os gregos mantêm superioridade cultural, social, política e econômica. Eles permanecem imunes a qualquer influência daqueles que foram helenizados e que adotaram a cultura helênica indiscriminadamente e sem questioná-la. Há pouca consideração de ações ou reciprocidade. Portanto, a Helenização é um processo binário e unidirecional. Essa interpretação dominou a nossa visão por quase todo o século XX, do período entre-guerras, quando as colônias gregas eram consideradas gloriosas contrapartes, até as próprias colônias europeias.

Todavia, no início dos anos 1990, a arqueologia começou a ser influenciada pela desconstrução pós-moderna que começou no discurso intelectual ocidental mais abrangente durante os anos 1980, especialmente o surgimento do pós-colonialismo através do trabalho de Edward Said and Gayatri Spivak. Em especial, tais contra-narrativas, como as desconstruções das meta-narrativas do discurso colonial, inspiraram estudos arqueológicos para reconsiderar as suas interpretações das colonizações grega e romana ao explorar seu impacto da perspectiva dos colonizados (Cf. Hodos, 2014: 24-30). Exames detalhados da utilização e prática da cultura material dentre os povos nativos revelaram que a adoção indiscriminada de bens e práticas estrangeiras não estava ocorrendo. Por exemplo, observou-se em inúmeros lugares, tais como a Sicília, Norte da África e França, que as comunidades nativas eram muito seletivas em relação ao que elas escolhiam adquirir de seus vizinhos estrangeiros, principalmente, no que se refere a certas formas cerâmicas ou características arquitetônicas. Além disso, a taxa de aquisição podia ser décadas ou até mesmo séculos depois da chegada dos gregos em uma região (Cf. Dietler, 2010; Hodos, 2006). Uma interpretação da Helenização simples não se encaixava com tais evidências. Ao invés disso, esses exemplos se encaixam melhor em um modelo híbrido de interpretação. Quando conectada à prática cultural, a hibridização pode ser considerada como a mistura cultural que surge de práticas de origens mistas (Friedman in: Werbner e Modood, 1997: 70-89, 88; Burke, 2009: 34). As pessoas e os objetos materiais em tais situações criam novas práticas sociais e materiais. Frequentemente, essas práticas

Heródoto, Unifesp, Guarulhos, v.4, n.1 - 2019.1. p. $45-73$

DOI: $10.34024 /$ herodoto. \% Y.v\%v.10087 
irão combinar tanto as formas coloniais quanto as tradicionais, porém serão uma mistura exclusiva para o grupo em questão. Em resumo, a hibridização é um processo ativo relacionado a agentes sociais e suas negociações e interações, em situações de contato cultural. Ela também é um processo temporalmente específico e localmente contextualizado.

Interpretações da Idade do Ferro Mediterrânea inspiradas pelo póscolonialismo que focam nas experiências dos colonizados têm algumas vezes sido acusadas de serem nada mais do que algo politicamente correto. Assim, na edição de 1999 de The Greeks Overseas, Boardman se pergunta se a recente ênfase nas experiências dos colonizados é meramente parte de um "empurrão [dos] padrões modernos desejados sobre a antiguidade e criação de pressupostos sobre os preconceitos de gerações atuais de acadêmicos. " (Boardman, 1999: 268). E ele não está sozinho (Cf. Domínguez, 2012: 205-218). Essas críticas refletem uma insatisfação com a mudança de ênfase porque, às vezes, o resultado parece retirar o colonizador da narrativa, especialmente, quando a adaptação ocorre a longo prazo. Na realidade, entretanto, os trabalhos pós-coloniais nunca negaram que as culturas coloniais tiveram um impacto profundo naqueles denominados colonizados. Ao contrário, o discurso pós-colonial tem explicitamente buscado enfatizar as ações dos colonizados e ressaltar que as mudanças que se seguiram nas populações locais eram muito mais sutis do que simplesmente a adoção indiscriminada dos estilos de vida coloniais. Contudo, há momentos nos quais a escala temporal de adaptação sugere que a origem explicitamente grega das formas ou práticas havia sido perdida no tempo, tal que o uso de tais estilos ou costumes pode não ter mais tido qualquer associação significativa com as tradições helênicas.

Até o final dos anos 1990 e início dos anos 2000, reações ao quadro helênico de interpretação haviam tomado duas trajetórias distintas (Hodos, 2014: 27). A primeira tinha maior ênfase nas diversidades de "ser grego." Isto viu a desconstrução da noção de que as colônias gregas eram réplicas de suas cidades-mãe, com os acadêmicos, por sua vez, enfatizando sua diversidade (Cf. Dougherty e Kurke, 2003; Lomas, 2004; Tsetshkladze, 2006). Isso também levou a desafios a um conceito unificado dos "gregos" como uma entidade cultural (Hall, 2002). Todavia, eu já argumentei em outros lugares que ainda há um número suficiente de características comuns, que ainda somos capazes de discutir uma noção coletiva dos gregos (Hodos, 2009). A segunda ênfase extraiu o papel das populações nativas na relação grego vs. não-grego. Estudos demonstraram que o uso de quaisquer características gregas, seja a 
cerâmica, arquitetura, formas de sepultamento, escrita ou outras, foi gradual e seletivo de forma apropriada às circunstâncias locais (Cf. Dietler, 2010; Hodos, 2006).

O melhor exemplo fenício desta mudança de paradigma é visto nas interpretações do papel do Tophet, locais a céu aberto para rituais nos quais crianças eram sacrificadas e bebês sepultados como parte das práticas religiosas fenícias. Tophets foram encontrados predominantemente nas colônias ocidentais, embora exemplos do Oriente Próximo, além dos territórios fenícios, também tenham sido identificados (por exemplo, Tell Sukas). Apesar disso, mesmo assim, entende-se que o tophet reflete práticas pátrias. Moscati tinha certeza disso quando disse: "Não há evidências desses lugares sagrados na Fenícia, de fato, mas não há nenhuma dúvida que eles existiram, se acrescentarmos às evidências bíblicas as vastas provas fornecidas pelas escavações nas colônias ocidentais, " (Moscati, 1968: 77) aderindo à noção de uma colônia como a réplica da cidade-mãe no mundo fenício de modo geral. Atualmente, entretanto, abordagens mais sutis reconhecem uma variabilidade no que tange a função do Tophet e as variações são consideradas significativas para as circunstâncias locais, ao invés de reflexos de interpretações desinformadas de práticas amplamente compartilhadas (Aubet, 2001: 250-256; Quinn, 2018: 91-112). Essa palavra nunca aparece em documentos fenícios ou púnicos, portanto, nossa compreensão da função e importância do que denominamos Tophets em contextos fenícios/púnicos é totalmente ética. Tratava-se de um santuário como outros, no qual as pessoas podiam fazer transações com os deuses. Porém, havia variações tremendas nos métodos de sepultamento e comemoração em contextos Tophet. Análises recentes revelam que o prestígio social era enfatizado na colocação das estelas. A presença de um Tophet também é associada a outras características de urbanização, na medida em que ele pode ser considerado a primeira expressão do caráter urbano do assentamento, onde ele servia tanto as comunidades cívicas quanto as territoriais (Quinn in: Xella, 2013: 23-48). Em suma, o pensamento atual é que o Tophet é uma marca geral para diferentes realidades arqueológicas e conceituais por todo o mundo fenício, ao invés de um elemento claramente fenício-púnico. Como Jo Crawley Quinn recente e incisivamente comentou: "Se houve uma cultura diaspórica fenícia ou púnica ocidental corporativa, os santuários Tophet não faziam parte dela." (Quinn in: Xella, 2013: 40).

Agora, de nossa história acadêmica, nos encontramos com vários conjuntos de evidências que criaram perspectivas polarizadoras: as 
práticas compartilhadas que originalmente deram início a noções como Helenização, a variabilidade na prática do que era ser grego e fenício e o ressurgimento de práticas locais perante a propagação e impacto das culturas helênica e fenícia. Cada um, separadamente, tem seu mérito, como gerações de acadêmicos do passado e do presente já demonstraram. A questão é uma de escala de perspectiva. Por um lado, ainda há a esmagadora adoção, principalmente, da cultura material grega em uma grande área. Por outro lado, quando consideradas de uma perspectiva local, o uso de tais objetos é variável e localmente significativo. Logo, como pode uma interpretação ser rejeitada em favor de outra? Para reabilitar essas perspectivas aparentemente contrastantes em uma narrativa mais complacente, os acadêmicos estão recorrendo cada vez mais a teorias de globalização (Cf. Vlassopoulos, 2013; Sherratt in: Hodos, 2017: 602-617; Dommelen in: Hodos, 2017: 618-633; Müller, 2016).

\section{Uma Idade do Ferro Mediterrânea globalizada?}

Vamos retornar aos oito critérios da globalização de Jennings e verificar se podemos identificá-los na Idade do Ferro Mediterrânea, conectados por redes de colônias gregas e fenícias, que ligaram o norte e o sul e o leste e o oeste. Embora haja muitos exemplos que poderiam ser selecionados para ilustrar as oito características, aqui, eu apresento apenas uma breve seleção. A maioria delas foca na Sicília, onde gregos e fenícios coexistiram entre si, bem como com comunidades nativas. Assim, a ilha apresenta um dos melhores meios de examinar as conectividades complexas no antigo Mediterrâneo. No entanto, breves comparações com outras regiões também são fornecidas.

Primeiro, temos a compressão no tempo e no espaço. Para a Idade do Ferro Mediterrânea, eu argumentaria que realmente temos uma sensação de compressão no tempo e no espaço. O estabelecimento de assentamentos gregos e fenícios ao redor do Mediterrâneo possibilitou a comunicação regular e frequente por toda a bacia Mediterrânea. Tal comunicação, por necessidade, era uma mistura de navegação de cabotagem de longa distância e localizada. ${ }^{5}$ Foi por meio desses assentamentos que a cultura material grega e fenícia se propagou tão extensivamente ao redor do Mediterrâneo. O fato de a cultura material grega ter sido amplamente adotada é discutido abaixo. A questão é que

5 A ênfase de Horden, Purcell, Corrupting Sea. Para um estudo de caso, veja Justin Leidwanger, "Modeling distance with time in ancient Mediterranean seafaring: a GIS application for the interpretation of maritime activity," Journal of Archaeological Science 40.8 (2013): 3302-08.

Heródoto, Unifesp, Guarulhos, v.4, n.1 - 2019.1. p. $45-73$

DOI: $10.34024 /$ herodoto. \% Y.v\%v.10087 
os próprios assentamentos criavam pontos de interseção comercial, pois esses colonos adquiriam bens e objetos, culturalmente familiares, para uso próprio e para trocar com as comunidades vizinhas, que poderiam ter sido de culturas diversas. Além disso, o caráter permanente desses assentamentos introduziu uma cultura material não portátil, como estilos arquitetônicos e características culturais não materiais, tais como, práticas sociais e religiosas, a essas outras, cujos elementos também foram adotados posteriormente. Coletivamente, elas criaram um sentimento de "estar em apenas um lugar" por todo o Mediterrâneo.

Em contrapartida, durante a Idade do Bronze, interações regulares e frequentes, do tipo que cria um sentimento de "estar em apenas um lugar", eram muito mais focadas ao redor do Egeu (Knappet, Evans e Rivers, 2008: 1009-1024; Knappet, Evans e Rivers, 2011: 1008-1023). Por natureza e de modo geral, elas eram de menor duração. Embora haja evidências de trocas a maiores distâncias, tais como, entre o mundo micênico e a Sicília (Leighton, 1999: 170-180; Wijngaarden, 2002), essas parecem ser irregulares e excepcionais. Assim, foi apenas durante a Idade do Ferro que podemos argumentar que houve um sentimento de compressão no tempo e no espaço por todo o Mediterrâneo (Sherratt in: Hodos, 2017: 602-617).

O segundo é a desterritorialização. Ao longo dos séculos IX e VIII, a quantidade e variedade de itens em circulação ao redor do Mediterrâneo em mais do que apenas contextos elitistas sugerem a evolução do comércio. Vinhos, óleos, metais e cerâmicas são os itens materiais mais óbvios, mas outros bens que não deixam pegadas arqueológicas tão evidentes incluem têxteis, alimentos e até mesmo escravos. No entanto, talvez seja principalmente com a cerâmica que percebamos isso.

Assentamentos gregos e fenícios ao redor do Mediterrâneo começaram a produzir seus próprios estilos de cerâmica, embora fossem derivados de repertórios culturais importados. Desta forma, na Sicília, vemos o surgimento da cerâmica Sikeliote (grega-siciliana), que pegou tradições emprestadas de Corinto, Ática e do leste grego (Hodos, 2006; Hodos, 2010: 81-106). Na França (Marselha), vemos o desenvolvimento de Utensílios Beges Coloniais e Monocromo Cinza, o primeiro se tornou o padrão das louças do assentamento (Dietler, 2010). Os fenícios da Sardenha, Sicília, Malta e Cartago compartilhavam uma produção regional koine que derivava sobretudo das formas do leste do Mediterrâneo (como, por exemplo, ânforas geométricas bicromadas, jarras em forma de "cogumelo", enócoas trifólias, urnas e pratos) (Hodos in: Knapp e Dommelen, 2014; 214-229). Características dos utensílios Heródoto, Unifesp, Guarulhos, v.4, n.1 - 2019.1. p. $45-73$

DOI: $10.34024 /$ herodoto. \% Y.v\%v.10087 
gregos coloniais foram incorporadas às produções nativas. Na Sicília, por exemplo, as comunidades sicilianas rapidamente adotaram o uso de enócoas trifólias. As enócoas sicilianas dos séculos VI e V continuaram a utilizar padrões geométricos derivados de importações do século VIII e do início do século VII, ao invés dos padrões contemporâneos que as próprias colônias gregas produziam e importavam (Hodos in: Attema, Nijboer e Zifferero, 2005: 103-108).

O terceiro é a padronização. Uma das características mais marcantes do primeiro milênio AEC foi a disseminação do alfabeto grego pelo Mediterrâneo. Derivado do alfabeto fenício no final do século IX AEC, exemplos antigos do alfabeto grego são frequentemente associados a um sentimento de propriedade, através de algumas letras isoladas, inscrições de posse e dedicatórias (Powell, 2012: 227-244). Os contextos fúnebres e dedicatórios de muitas dessas inscrições mais antigas sugerem ainda que a escrita servia propósitos sociais mais diversificados, além da comunicação linguística direta. Com isso em mente, a propagação da escrita para não gregos e não fenícios tem que ser considerada em uma esfera social.

Na Sicília, escritos gregos foram inicialmente adotados durante o século VI pelas populações locais para expressar os dialetos falados, normalmente seguindo a formação do assentamento grego mais próximo (Hodos, 2006: 147-153). Portanto, as comunidades ao redor do Etna adotaram a escrita da Catânia, enquanto aquelas nos Montes Ibleus e ao redor da Planície de Catânia utilizavam a versão em uso em Siracusa e Megara Iblea. A escrita de Gela servia como modelo para os assentamentos nativos no interior central siciliano, enquanto Selinunte fez mais ou menos o mesmo para as comunidades do oeste da Sicília. O fenício, usado pelos assentamentos fenícios na Sicília a partir do século VI, não foi adotado. As inscrições são frequentemente pouco mais do que breves expressões de propriedade ou cumprimentos, esculpidas em copos e taças. Isto sugere uma relação explícita entre o consumo de vinho e a escrita, talvez, com a inscrição aumentando o status do dono do utensílio. O grego passa a ser a língua das comunicações oficiais até o século IV. Em contrapartida, em Lattes na França, o etrusco foi utilizado pela primeira vez no século VI e o grego, apenas a partir da metade do século V. Nenhum dos dois foi adaptado mais amplamente para expressar os dialetos locais, até muitos séculos mais tarde. Entretanto, quando se tratava de grego, ele era favorecido (Dietler, 2010: 70-72).

Fica claro que, ao invés da simples e direta adoção do alfabeto grego e suas funções, o uso de letras foi modificado para se encaixar aos valores e Heródoto, Unifesp, Guarulhos, v.4, n.1 - 2019.1. p. $45-73$

DOI: $10.34024 /$ herodoto. \% Y.v\%v.10087 
procedimentos locais. A longa evolução de sua adaptação também indica que uma simples emulação não era o objetivo. Do contrário, a natureza e extensão do uso do grego e/ou de seu alfabeto, além dos assentamentos coloniais gregos, parece depender mais das circunstâncias históricas locais, das especificidades do assentamento e de suas conexões e interações regionais. Não se trata do reflexo de um padrão geral ou da velocidade em que ocorria o desenvolvimento linguístico.

O quarto é a desigualdade. Para a Idade do Ferro, nenhuma cidadeestado surgiu como a todo-poderosa até os séculos VI e V, quando Cartago se consolidou como a base do poder fenício depois da destruição de Tiro pelos babilônios no início do século VI e Atenas emergiu como uma força política e econômica difícil de sobrepujar. Todavia, alguém poderia argumentar que as próprias redes de assentamentos gregos e fenícios criavam um meio coletivo de comunicação e interação em um campo mais abrangente. Elas não foram dominadas por uma única cidade até mais tarde, quando Cartago e Atenas emergiram como pontos focais dessas redes comerciais, amalgamando poder e consolidando recursos fiscais e controle.

Do século IX até os séculos VI e V, nem todas as regiões estavam igualmente conectadas a essas redes (não estou sugerindo que ficaram igualmente conectadas após esse período, mas isso está além do escopo deste trabalho). Algumas áreas tinham relacionamentos mais próximos do que outras em determinados períodos da Idade do Ferro. Um recente estudo comparativo da Baía de Cádis, Baía de Nápoles, Golfo de Oristano e do Golfo de Leão - todos os quais foram estabelecidos pelos gregos e/ou fenícios - revela diversas datas e velocidades de conexão entre o Mediterrâneo em geral e o interior acessado por meio desses portos e que até mesmo a proximidade de tais conexões enfraqueceu com o passar do tempo (Dommelen in: Hodos, 2017: 618-633). Uma abordagem local, de baixo para cima é necessária para vermos a desigualdade de e em uma visão globalizada do mundo.

O quinto é a homogeneização. O entendimento da cerâmica grega, em particular, nas zonas adjacentes aos locais onde os gregos fundaram seus assentamentos, logo depois que eles se estabeleceram nessas áreas (independentemente de discussões sobre as relações comerciais anteriores ao estabelecimento desses sítios) e a rápida imitação de algumas das formas e padrões pelos ceramistas nativos demonstram um grande apreço por tais produtos da parte de diversos grupos culturais. Se isso também era um indicativo do desejo de ser culturalmente parecido com os produtores desses objetos ou não, o uso de tais itens em contextos Heródoto, Unifesp, Guarulhos, v.4, n.1 - 2019.1. p. $45-73$

DOI: $10.34024 /$ herodoto.\%Y.v\%v.10087 

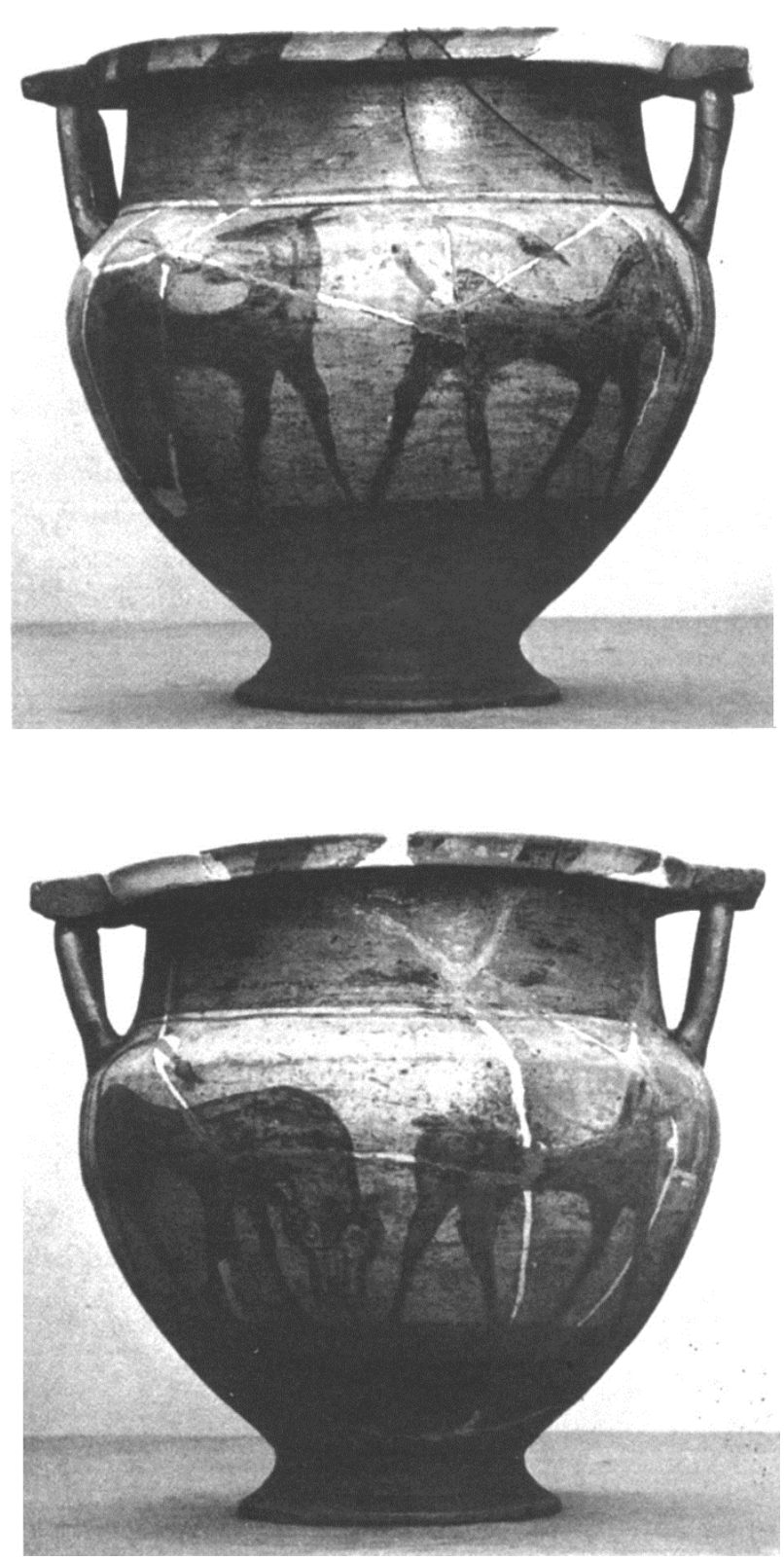

Figura 1. Cratera de Sabucina.

semelhantes, especialmente domésticos, ritualísticos e fúnebres, reflete elementos de práticas compartilhadas, sejam elas originalmente nativas ou adaptativas. Portanto, esta combinação do uso de objetos importados e/ou copiados em contextos similares apresenta um grau de homogeneização pelo mundo Mediterrâneo nesse período. Podemos argumentar que a distribuição e o volume são desiguais geográfica e temporalmente ao longo da Idade do Ferro, porém, há um alto nível de uniformidade que pode ser observada. Este uso aparentemente bastante difundido das formas culturais materiais gregas e em contextos de uso semelhantes são o que originalmente deram início às ideias de Helenização. A reconstrução adicional de vários assentamentos seguindo as formas usadas nos assentamentos gregos (e fenícios)

e a adaptação do alfabeto grego pelas populações locais reforçam, mais ainda, um sentimento de homogeneização ao longo da Idade do Ferro (Cf. Hodos, 2006; Dietler, 2010).

O sexto é a heterogeneidade cultural. Isso é bem exemplificado pelas variações nas cerâmicas que misturam uma série de ideias. Um desses exemplos é uma cratera de Sabucina, um sítio nativo na parte central da Sicília (Figura 1) (Hodos, 2006: 136-140). A decoração nesse utensílio em particular é um par de animais selvagens, um de cada lado, em um friso. Isto é reminiscente das procissões animais heráldicas da metade da era coríntia, mas faltam ao exemplo de Sabucina os ornamentos de preenchimento e os detalhes entalhados, típicos dos produtos gregos. A cor da argila imita a coríntia, embora a forma do corpo e do pé sejam Heródoto, Unifesp, Guarulhos, v.4, n.1 - 2019.1. p. 45-73

DOI: $10.34024 /$ herodoto.\%Y.v\%v.10087 
áticas em formato. Enquanto as importações para a colônia grega Gela, ali perto, e sua própria produção de cerâmica podem ter servido de inspiração, o artista local em Sabucina criou uma nova, claramente local justaposição de ideias. 


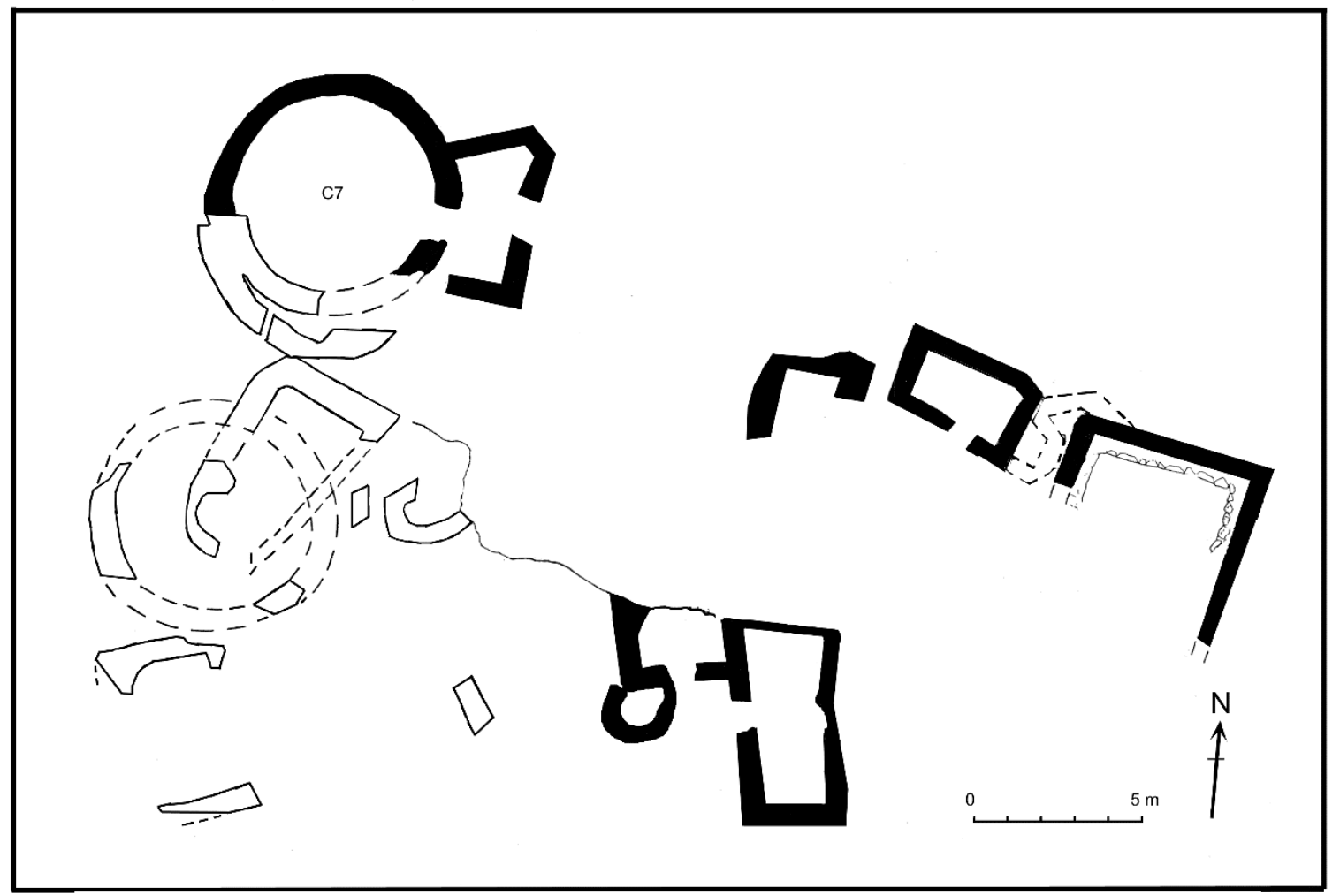

Figura 2. Planta baixa de Sabucina, incluindo a estrutura circular C7.

O sétimo é a reinserção da cultura local. Usando a Sicília como exemplo novamente, a forma arquitetônica doméstica tradicional era a casa circular (Procelli, 2003). Na Sicília, durante o século VI, uma série de sítios sicilianos adotaram planejamentos urbanos envolvendo blocos articulados ao longo de ruas grandes e estreitas, arquitetura retilínea e muros ao redor da cidade inteira - características associadas aos ambientes urbanos gregos e fenícios. Assim, é digno de nota que, durante o século VI, uma série de centros nativos, embora tivessem abraçado a arquitetura retilínea, mesmo assim também mantiveram grandes estruturas circulares que serviam como templo ou santuário - um propósito cultural bastante explícito. Um desses edifícios foi construído em Sabucina nesse período, por exemplo (Figura 2). O que é especialmente notável é que ele tinha um vestíbulo in antis rodeado por duas colunas para criar um pórtico. Esta é uma justaposição ímpar de desenvolvimentos arquitetônicos e tradicionais sicilianos que derivam de formas gregas: ela adere a formas circulares tradicionais e era reservada para edificações religiosas (de acordo com as práticas sicilianas atuais), no entanto, ela concomitantemente adota a noção de um pórtico de estruturas religiosas gregas (Hodos, 2010: 92-93).

Finalmente, o oitavo é a vulnerabilidade. A conectividade complexa leva à interdependência por causa das inúmeras e profundamente Heródoto, Unifesp, Guarulhos, v.4, n.1 - 2019.1. p. 45-73

DOI: $10.34024 /$ herodoto. \% Y.v\%v.10087 
incorporadas conexões entre vários grupos. O sistema globalizado criado pelas redes de assentamentos gregos e fenícios envolveu as populações locais em seus conflitos uns com os outros. Até o século VI, com a destruição de Tiro no Mediterrâneo oriental, Cartago desempenhou um papel político mais abertamente ativo na área central do Mediterrâneo, emergindo como o ponto focal para a civilização fenícia. Este é o início da era púnica da história fenícia. Isto começou na Sicília, quando Cartago assegurou o controle sobre as cidades fenícias no oeste da Sicília. Isso atraiu gregos e cartagineses para um conflito direto entre si, com as próprias populações nativas locais se envolvendo no conflito ao se aliarem a um ou ao outro, para elas próprias ganharem controle territorial.

\section{Conclusões}

Para concluir, pode-se argumentar que temos todas as marcas de uma globalização moderna no primeiro milênio AEC. Contudo, talvez seja melhor se referir a ela como uma era globalizante ao invés de globalizada. Fica claro pela trajetória a longo prazo que o passado nos dá que o desenvolvimento da globalização na Idade do Ferro Mediterrânea foi um processo irregular, tanto temporal quanto espacialmente. Foram necessários quase quatrocentos anos, do século IX ao século $\mathrm{V}$, para essas conexões complexas se desenvolverem completamente. Esses processos começaram quando os gregos e fenícios criaram infraestruturas de rede físicas ligadas por uma cultura comum - suas colônias - e as usaram para expandir seus empreendimentos comerciais e exercer influência política. Por meio de suas redes mercantilistas, ideias sobre formas artísticas e arquitetônicas se propagaram e mecanismos para facilitar a comunicação foram adotados e adaptados. Isso criou um sentimento de compressão no tempo e no espaço através da sensação de "estar em apenas um lugar" da globalização, mas essas adaptações foram desiguais em sua adoção com o passar do tempo e nos diferentes lugares.

Como isso se compara a outros paradigmas Mediterrâneos recentes: mais especificamente, a conectividade promovida por Horden e Purcell (2000), a perspectiva movida a desenvolvimento econômico oferecida por Broodbank (2013) e a abordagem em rede de Malkin (2011) ?. Todos esses compartilham um interesse comum no que torna o Mediterrâneo um mundo conectado. Para Horden e Purcell, trata-se de uma combinação de interação microrregional, a facilidade de comunicação entre as duas microrregiões e em maiores distâncias e a instabilidade climática e ecológica na região em geral (o que encoraja o excesso de produção e a

Heródoto, Unifesp, Guarulhos, v.4, n.1 - 2019.1. p. $45-73$

DOI: $10.34024 /$ herodoto. \% Y.v\%v.10087 
redistribuição). Logo, eles veem uma interação dinâmica entre atividades humanas e recursos naturais como a narrativa que embasa a história Mediterrânea. A unidade nessa narrativa se encontra na desunião em cada um dos três aspectos: a fragmentação e multiplicidade das microrregiões, a instabilidade inerente do ambiente natural e a variabilidade da mobilidade.

Broodbank amplia esta perspectiva ao examinar as redes de pessoas, em constante mutação, ao redor da região Mediterrânea. Assim, o movimento de pessoas, grupos, objetos e ideias se torna o personagem principal, com resultantes concorrências e interdependências econômicas e políticas, que acompanhavam o entendimento cada vez mais compartilhado de riqueza e indicadores de status, estilos artísticos e até mesmo sincretismo religioso. Isto é especialmente o caso da sua discussão sobre a própria Idade do Ferro.

A ênfase de Malkin está nas redes que sustentam essa conectividade, principalmente, no mundo grego. Ele demonstra que os conceitos de Grécia e "os gregos" evoluíram das redes multiétnicas, culturais e direcionais do período e que foram o movimento e as distâncias entre os gregos que geraram suas similaridades e consolidaram suas identidades compartilhadas sobre uma ampla área geográfica.

Todas as três perspectivas cabem confortavelmente sob o guarda-chuva dos estudos sobre globalização. Um estudo cuidadoso dos três trabalhos e uma análise dos exemplos apresentados acima demonstram que a conectividade da Idade do Ferro ocorreu em contextos geográficos e ecológicos específicos. Uma abordagem de baixo para cima, através de estudos de caso, também ressalta o fato de que as conectividades não se desenvolveram linearmente nem na mesma velocidade, e elas não eram estáveis, embora seu alcance se estendesse muito além das zonas litorâneas mediterrâneas. Portanto, a globalização é melhor explorada de duas direções: a abordagem de baixo para cima de estudos de caso individuais e localizados e a análise de cima para baixo das práticas compartilhadas. ${ }^{6} \mathrm{O}$ que liga as duas são as redes de conectividade por meio das quais bens e ideias se movem. As redes facilitam o desenvolvimento das práticas compartilhadas. As pessoas engajadas nessas redes responderão individualmente à sua participação, com algumas se engajando mais intensamente (em algumas áreas da conectividade), e outras menos, e cada uma irá responder às suas

\footnotetext{
${ }^{6}$ Conforme explícitamente defendido por van Dommelen, "Classical Connections," 62829. (Dommelen in: Hodos, 2017: 618-633).
}

Heródoto, Unifesp, Guarulhos, v.4, n.1 - 2019.1. p. 45-73

DOI: 10.34024/herodoto.\%Y.v\%v.10087 
interações na rede globalizada de forma a atender as necessidades e demandas de seu próprio sistema sociocultural.

Centros dos assentamentos e suas periferias - o tema do presente volume - têm um papel a desempenhar em um sistema globalizado. As redes sustentam as conectividades de uma visão globalizada, pois a noção de rede nos dá ferramentas para analisar as conectividades ao longo do espaço, bem como as propriedades emergentes dessas conexões ao longo do tempo (Knappett in: Hodos, 2017: 29-41). Essas redes operam através de seus pontos de interseção, que são os próprios sítios, assim, dando às redes uma dimensão geográfica e física. Todavia, nenhum sistema de interação é igualmente balanceado. Sempre haverá centros mais fortes e mais fracos e ligações mais fortes e mais fracas que unem locais diferentes. É aqui que a noção de assentamentos e periferias entra em um quadro de globalização. Esses também terão uma variedade de conectividades, cada uma irá diminuir e fluir ao longo do tempo.

Por esses motivos, eu argumento que uma perspectiva de globalização nos permite reabilitar os vários conjuntos de dados utilizados como base para a promoção de várias perspectivas, historicamente e atuais. Isso inclui o uso bastante disseminado de cerâmicas e formas arquitetônicas gregas, que, originalmente, deram início ao modelo de Helenização, e a variabilidade dentro de tal utilização, que subsequentemente fomentou interpretações de hibridização. Agora, fica claro que havia variação das práticas entre as próprias colônias gregas e entre as próprias colônias fenícias, que evidenciam padrões semelhantes. Um quadro de globalização de interpretação nos permite examinar o equilíbrio entre as características compartilhadas, que nos permitem discutir "os gregos" e "os fenícios", enquanto, ao mesmo tempo, reconhecendo as diferenças nas práticas de ser grego ou fenício. Podemos também reconhecer a tensão encontrada nas práticas compartilhadas entre os grupos culturais diferentes e as articulações de suas identidades sociais que contrastam com as semelhanças nascidas de um engajamento mais abrangente. Isso é parte da essência da globalização. Uma perspectiva globalizada também permite que os fenícios e gregos sejam reabilitados juntos na narrativa arqueológica do Mediterrâneo. As atividades dos fenícios, e suas interações com os gregos e outros povos no Mediterrâneo, são um aspecto tão essencial para compreender a relação grego-não-grego quanto os gregos são para o desenvolvimento cultural fenício no Mediterrâneo. Seu estudo não deveria ser separado por disciplina.

Em suma, as características comuns amplamente compartilhadas que se desenvolveram ao longo do Mediterrâneo durante a Idade do Ferro não

Heródoto, Unifesp, Guarulhos, v.4, n.1 - 2019.1. p. $45-73$

DOI: $10.34024 /$ herodoto. \% Y.v\%v.10087 
refletem a Helenização ou a Fenicianização, mas as amplamente entendidas Mediterraneanizações (Morris, 2003: 30-55) moderadas por identidades localizadas fortemente coordenadas. Por esta razão, uma abordagem de globalização cria um entendimento muito mais profundo das complexidades sociais que evoluíram durante a Idade do Ferro pelo Mediterrâneo do que fomos capazes de apreciar anteriormente.

\section{Referências bibliográficas}

"Globalization Thinking and the Past," em The Routledge Handbook of Archaeology and Globalization, ed. HODOS, Tamar (Londres: Routledge, 2017), 54-65.

AUBET, Marie Eugenia. The Phoenicians and the West: Politics, Colonies and Trade (Cambridge: Cambridge University Press, 2001), 250-56;

BELOCH, Karl Julius. Griechische Geschichte, volume 1.1 (Strassburg: K.J Trübner, 19132), 229-32.

BOARDMAN, John. The Greeks Overseas (Londres: Thames e Hudson, 1999), 38, 190, 268.

BROODBANK, Cyprian. The Making of the Middle Sea (Londres: Thames e Hudson, 2013).

BURKE, Peter. Cultural Hybridity (Cambridge: Polity Press, 2009), 34.

CALDWELL, Melissa. "Domesticating the French Fry: McDonald's and consumerism in Moscow," Journal of Consumer Culture 4.1: (2004) 5-26.

DIETLER, Michael. Archaeologies of Colonialism. Consumption, entanglement and violence in ancient Mediterranean France (Berkeley e Los Angeles: University of California Press, 2010);

DOMÍNGUEZ, Adolfo. "Local Responses to Colonisation: Some Additional Perspectives," Ancient West and East 11 (2012): 205-18.

DOMMELEN, Peter van. "Classical Connections and Mediterranean Practices," em The Routledge Handbook of Archaeology and Globalization, ed. HODOS, Tamar. (Londres: Routledge, 2017), 618-33.

DOUGHERTY e KURKE. The Cultures Within Greek Culture (Cambridge: Cambridge University Press, 2003); 
FEATHERSTONE, Mike. Undoing Culture: Globalization, Postmodernism and Identity (Londres: Sage, 1995), 114.

FRIEDMAN, Jonathan. "Global Crises, the Struggle for Cultural Identity and Intellectual Pork Barrelling: Cosmopolitans versus Locals, Ethnics and Nationals in an Era of Dehegemonisation" in: Debating Cultural Hybridity: multi-cultural identities and the politics of anti-racism, eds. WERBNER, Pnina. MODOOD, Tariq (Londres: Zed Books, 1997), 70-89, 88;

GIDDENS, Anthony. The Consequences of Modernity (Cambridge: Polity Press, 1990);

GIDDENS, Anthony. The Consequences of Modernity (Stanford: Stanford University Press, 1990);

HALL, Jonathan. Hellenicity (Chicago: Chicago University Press, 2002).

HARVEY, David. The Condition of Postmodernity (Oxford: Blackwell, 1989).

HODOS, Tamar, "Stage Settings for a Connected Scene: Globalization and Material Culture Studies in the Early First Millennium BCE Mediterranean". Archaeological Dialogues 21.1 (2014): 24-30, 27.

HODOS, Tamar. "Changing Communities in Iron Age Sicily," em Communities and Settlements from the Neolithic to the Early Medieval Period: proceedings of the $6^{\text {th }}$ Conference in Italian Archaeology, Groningen, April 1517, 2003, eds. ATTEMA, Peter. NIJBOER, Albert. ZIFFERERO, Andrea. (Oxford: British Archaeological Reports, 2005), 103-08.

HODOS, Tamar. "Colonial Engagements in the Global Mediterranean Iron Age," Cambridge Archaeological Journal 19.2 (2009): 221-41.

HODOS, Tamar. "Colonisation and Cultural Developments in the Central Mediterranean," em Cambridge Handbook of the Mediterranean World in the Bronze-Iron Ages, eds. KNAPP, Bernard. DOMMELEN, Peter van. (Cambridge: Cambridge University Press 2014), 214-29.

HODOS, Tamar. "Global, Local and In Between: Connectivity and the Mediterranean," no Globalisation and the Roman World, eds. PITTS, Martin. VERSLUYS, Miguel John (Cambridge: Cambridge University Press, 2014), 240-53.

HODOS, Tamar. "Globalization and Colonization: A View from Iron Age Sicily," Journal of Mediterranean Archaeology 23.1 (2010): 81-106. 136-40. 147-53, 92-93.

Heródoto, Unifesp, Guarulhos, v.4, n.1 - 2019.1. p. $45-73$

DOI: $10.34024 /$ herodoto. \% Y.v\%v.10087 
HODOS, Tamar. "Globalization: Some Basics," em The Routledge Handbook of Archaeology and Globalization, ed. Tamar Hodos (Londres: Routledge, 2017), 3-11, 4, 5.

HODOS, Tamar. ed. The Routledge Handbook of Archaeology and Globalization (Londres: Routledge, 2017).

HODOS, Tamar. Local Responses to Colonisation in the Iron Age Mediterranean (Londres: Routledge, 2006).

HORDEN, Peregrine. PURCELL, Nicholas. The Corrupting Sea (Oxford: Blackwell, 2000).

JENNINGS, Justin. "Distinguishing Past Globalizations," em The Routledge Handbook of Archaeology and Globalization, ed. HODOS, Tamar (Londres: Routledge, 2017), 12-28, 14-16.

JENNINGS, Justin. Globalizations and the Ancient World (Cambridge: Cambridge University Press, 2011), 123-41;

KNAPPETT, Carl, "Globalization, connectivities and networks: an archaeological perspective," em The Routledge Handbook of Archaeology and Globalization, ed. HODOS, Tamar. (Londres: Routledge, 2017), 29-41.

KNAPPETT, Carl. EVANS, Tim. RIVERS, Ray. "Modelling Maritime Interaction in the Aegean Bronze Age," Antiquity 82 (2008): 1009-24;

KNAPPETT, Carl. EVANS, Tim. RIVERS, Ray. "The Theran Eruption and Minoan Palatial Collapse: New Interpretations Gained from Modelling the Maritime Network," Antiquity 85 (2011): 1008-23.

LEIGHTON, Robert. Sicily Before History (Londres: Duckworth, 1999) 17080;

LOMAS, Katheryn. ed. Greek Identity in the Western Mediterranean (Leiden: Brill, 2004);

MALKIN, Irad. A Small Greek World. Networks in the ancient Mediterranean (Oxford: Oxford University Press, 2011).

MOORE, Karl. LEWIS, David. The Origins of Globalization (Nova Iorque e Londres: Routledge, 2009). 
MORLEY, Neville. "Globalisation and the Roman Empire," in Globalisation and the Roman World, eds. Martin PITTS e Miguel John VERSLUYS (Cambridge: Cambridge University Press, 2014), 49-68.

MORRIS, Ian. "Mediterraneanization," Mediterranean Historical Review 18.2 (2003): 30-55.

MOSCATI, Sabatino. Il Mondo dei Fenici (Milan: Il Saggiatore, 1966).

MOSCATI, Sabatino. The World of the Phoenicians (Londres: Cardinal, 1968), 77.

MÜLLER, Christel. "Globalization, Transnationalism, and the Local in Ancient Greece," Oxford Handbooks, 2016, Online em: http:// www.oxfordhandbooks.com/view/10.1093/oxfordhb/978019993 5390.001.0001/oxfordhb-9780199935390-e-42.

PIETERSE, Jan Nederveen. "Rethinking Modernity and Capitalism: Add Context and Stir," Sociopedia Colloquium 1 (2014), 1-11.

PIETERSE, Jan Nederveen. Globalization and Culture (Malden: Rowman e Littlefield, 2015), 7-25, 67, 68.

POWELL, Barry. Writing: Theory and History of the Technology of Civilization (Chichester: Wiley-Blackwell, 2012), 227-44.

PROCELLI, Rosa Maria Albanese. Sicani, Siculi, Elimi (Milan: Longanesi, 2003).

QUINN, Jo Crawley, In Search of the Phoenicians (Princeton: Princeton University Press, 2018), 91-112.

QUINN, Jo Crawley. "Tophets in the Punic World," em The 'Tophet' in the Phoenician Mediterranean: Studi Epigrafici e Linguistici 29-30 (2012-13), ed. XELLA, Paolo. (Verona: Essedue, 2013), 23-48, 40.

ROBERTSON, Robbie. Three Waves of Globalisation: A history of a development global consciousness (Londres: Zed Books, 2003);

ROBERTSON, Roland. Globalizaton, Social Theory and Global Culture (Londres: Sage, 1992);

SHERRATT, Sue. "A Globalizing Bronze and Iron Age Mediterranean," in: The Routledge Handbook of Archaeology and Globalization, ed. HODOS, Tamar. (Londres: Routledge, 2017), 602-17; 
STEIGLITZ, Joseph. Making Globalization Work (Londres: Penguin, 2006), $3-24,5$.

TOMLINSON, John. Globalization and Culture (Chicago: Chicago University Press, 1992), 2.

TSETSHKLADZE, Gocha. ed., Greek Colonization: An account of Greek colonies and other settlements overseas (Leiden: Brill, 2006).

TSETSKHLADZE, Gocha. "Introduction: Revising Ancient Greek Colonisation," no Greek Colonisation: An Account of Greek Colonies and Other Overseas Settlements, ed. TSETSKHLADZE, Gocha (Leiden: Brill, 2006), xxiii-lxxxiii, xlix $(23-83,49)$

VLASSOPOULOS, Kostas. Greeks and Barbarians (Cambridge: Cambridge University Press, 2013);

WALDBAUM, Jane. "The Coming of Iron in the Eastern Mediterranean," no The Archaeometallurgy of the Asian Old World, ed. PIGGOT, Vincent C. (Filadélfia: Museu da Universidade da Pensilvânia, 1999), 27-57;

WALDBAUM, Jane. From Bronze to Iron: The Transition from the Bronze Age to the Iron Age in the Eastern Mediterranean (Göteborg: Paul Aström, 1978);

WALLERSTEIN, Immanuel. Geopolitics and Geoculture (Cambridge: Cambridge University Press, 1991);

WARD, Kevin. ENGLAND, Kim. "Introduction: Reading Neoliberalization," in Neoliberaliztion: States, Networks, Peoples, eds. WARD, Kevin. ENGLAND, Kim. (Oxford: Blackwell, 2007), 1-22;

WIJNGAARDEN, Gert Jan van. Use and Appreciation of Mycenaean Pottery in the Levant, Cyprus and Italy (1600-1200 BC) (Amsterdã: Amsterdam University Press, 2002).

YALÇIN, Ünsal. "Early Iron Metallurgy in Anatolia," Anatolian Studies 49 (1999): 177-87. 